\title{
Med-Score 24: A multivariable prediction model for poststernotomy mediastinitis 24 hours after admission to the intensive care unit
}

\author{
Mercedes Nieto-Cabrera, MD, PhD, ${ }^{\mathrm{a}, \mathrm{d}}$ Cristina Fernández-Pérez, $\mathrm{MD}, \mathrm{PhD}$, \\ Inés García-González, MD, ${ }^{\mathrm{a}}$ Juan Carlos Martin-Benítez, MD, PhD, ${ }^{\mathrm{a}, \mathrm{e}}$ Justo Ferrero, MD, ${ }^{\mathrm{a}}$ \\ María Bringas, $\mathrm{MD}, \mathrm{PhD},{ }^{\mathrm{a}, \mathrm{d}}$ Manuel Carnero, $\mathrm{MD}, \mathrm{PhD},{ }^{\mathrm{c}}$ Luis Maroto, $\mathrm{MD}, \mathrm{PhD},{ }^{\mathrm{c}}$ and \\ Miguel Sánchez-García, MD, $\mathrm{PhD}^{\mathrm{a}, \mathrm{e}}$
}

\section{ABSTRACT}

Objectives: Mediastinitis is a serious complication of heart surgery. In this study, we developed a bedside risk score for poststernotomy mediastinitis.

Methods: Data were prospectively collected from 4625 patients admitted to our intensive care unit after heart surgery (January 2005-June 2011). Mediastinitis was defined according to Centers for Disease Control and Prevention criteria. A logistic model was constructed in a randomly selected subgroup of 2618 patients and validated in a second cohort of 1352, as well as in a prospective cohort of 2615 (June 2011-December 2015). Model discriminatory power was assessed according to the area under the receiver operating characteristic curve (AUROC). The $\beta$ coefficients of the model were used to define 3 levels of mediastinitis risk as a score designated Med-Score 24. Its performance to predict mediastinitis was compared with that of the logistic EuroSCORE and Society of Thoracic Surgeons score.

Results: Ninety-four $(2.36 \%)$ patients developed mediastinitis. The risk factors identified as predictive of mediastinitis (AUROC 0.80 ) were 4 preoperative variables (age $>70$ years, chronic obstructive lung disease, obesity, and antiplatelet therapy) and 3 perioperative variables (prolonged ischemia, emergency reoperation, and prolonged intubation). AUROCs for the Society of Thoracic Surgeons score and logistic EuroSCORE were 0.63 and 0.55 , respectively, both differing significantly from the area calculated for Med-Score $24(P<.001)$.

Conclusions: The score developed showed excellent predictive power 24 hours after admission to the intensive care unit for mediastinitis risk. This simple tool helps stratify patients according to this risk, thus identifying high-risk patients for preventive measures. In our patient cohort, Med-Score 24 performed better than other scores used for this purpose. (J Thorac Cardiovasc Surg 2018;155:1041-51)

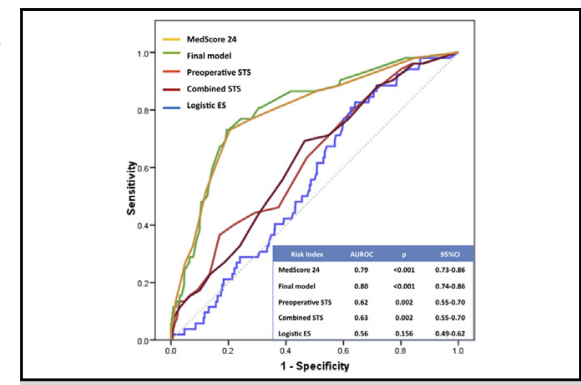

Predictive powers of mediastinitis risk scores for 3970 heart surgery patients.

\section{Central Message}

We present a new score to predict the risk of poststernotomy mediastinitis. This bedside score can be used within 24 hours after a patient undergoing major heart surgery is admitted to the ICU

\section{Perspective}

Poststernotomy mediastinitis is a serious complication of heart surgery. Our objective was to develop and validate a simple bedside mediastinitis risk score for use within 24 hours of major heart surgery. The rationale was that if we could accurately and quickly predict this postoperative complication, we could implement appropriate prevention strategies and reduce its impacts.

See Editorial Commentary page 1052.

\footnotetext{
From the ${ }^{\mathrm{a} C} \mathrm{Critical}$ Care Department, ${ }^{\mathrm{b}}$ Preventive Medicine Service, ${ }^{\mathrm{c}}$ Cardiac Surgery Department, and ${ }^{\mathrm{f} I n s t i t u t o ~ d e ~ I n v e s t i g a c i o ́ n ~ S a n i t a r i a ~ I d I S S C, ~ H o s p i t a l ~ C l i ́ n i c o ~ S a n ~}$ Carlos, Madrid, Spain; ${ }^{\mathrm{d}}$ Faculty of Medicine, Universidad Alfonso X el Sabio, Madrid, Spain; and ${ }^{\mathrm{e}}$ Faculty of Medicine, Universidad Complutense de Madrid, Madrid, Spain.

Read at the meeting of the European Society of Intensive Care Medicine (ESICM), Berlin, Germany, October 3-7, 2015.

Received for publication Feb 15, 2017; revisions received Sept 7, 2017; accepted for publication Sept 25, 2017; available ahead of print Dec 19, 2017.

Address for reprints: Mercedes Nieto-Cabrera, MD, PhD, Martin Lagos s/n, Madrid 28040, Spain (E-mail: mernietoc@gmail.com).

$0022-5223 / \$ 36.00$

Copyright (C) 2017 by The American Association for Thoracic Surgery

https://doi.org/10.1016/j.jtcvs.2017.09.160
}

Despite advances in heart surgery and strategies for preventing surgical-site infection (SSI), poststernotomy mediastinitis (PSM) remains a major concern. The

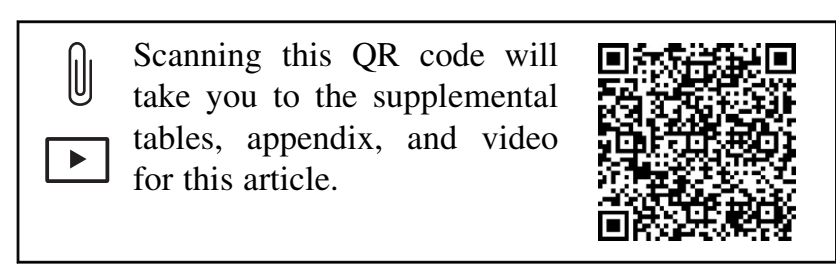




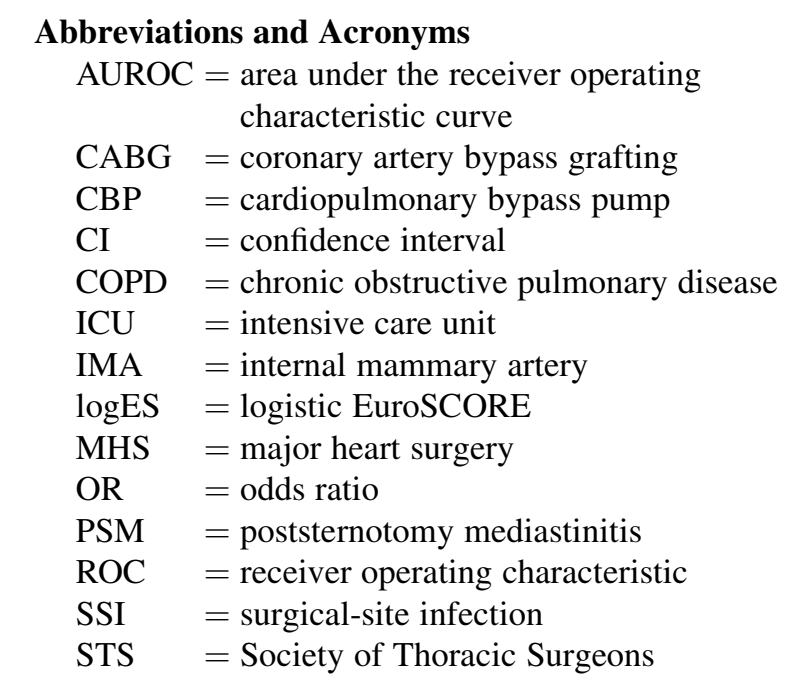

incidence of this serious complication has been estimated at 0.5 to $4 \%,{ }^{1-3}$ and it has been associated with prolonged hospital stay and increased mortality and cost. ${ }^{4-9}$

Risk scoring systems are useful for predicting postoperative complications and implementing appropriate prevention strategies. The impact of PSM on morbidity and mortality underscores the importance of accurately defining risk factors to identify high-risk patients both for pre- and perioperative prevention and for increased diagnostic awareness and early therapy. In numerous studies, several risk factors for developing PSM have been described. ${ }^{10,11}$ A recent review has also reported the variables needed for the European Association for Cardio-Thoracic Surgery

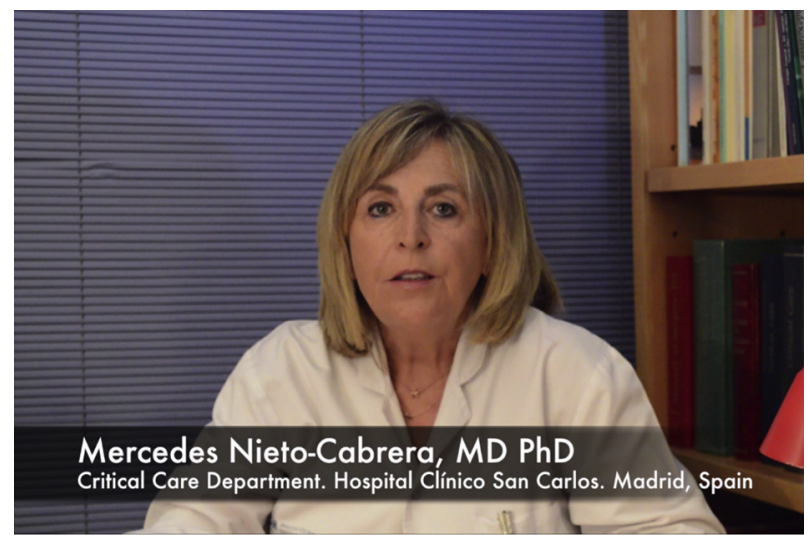

VIDEO 1. Potential impacts of Med-Score 24. Video available at: http:// www.jtcvsonline.org/article/S0022-5223(17)32719-8/fulltext.

risk-prediction model, although this model does not include mediastinitis as an endpoint. ${ }^{12}$ Scores predicting mediastinitis have also been developed for different regions. ${ }^{1,13-23}$ However, these risk scores have not always been validated or have shown suboptimal performance, ${ }^{24,25}$ and it is not clear how generalizable to different patient settings these scores are. ${ }^{26}$

The objectives of our study were to identify independent risk factors for PSM to include in a specific predictive model for the bedside assessment of patients who undergo heart surgery 24 hours after their admission to the intensive care unit (ICU). The scoring system developed, designated MedScore 24 , was then validated in a prospective cohort and its performance compared with that of other established scores (Video 1). ${ }^{1,11}$

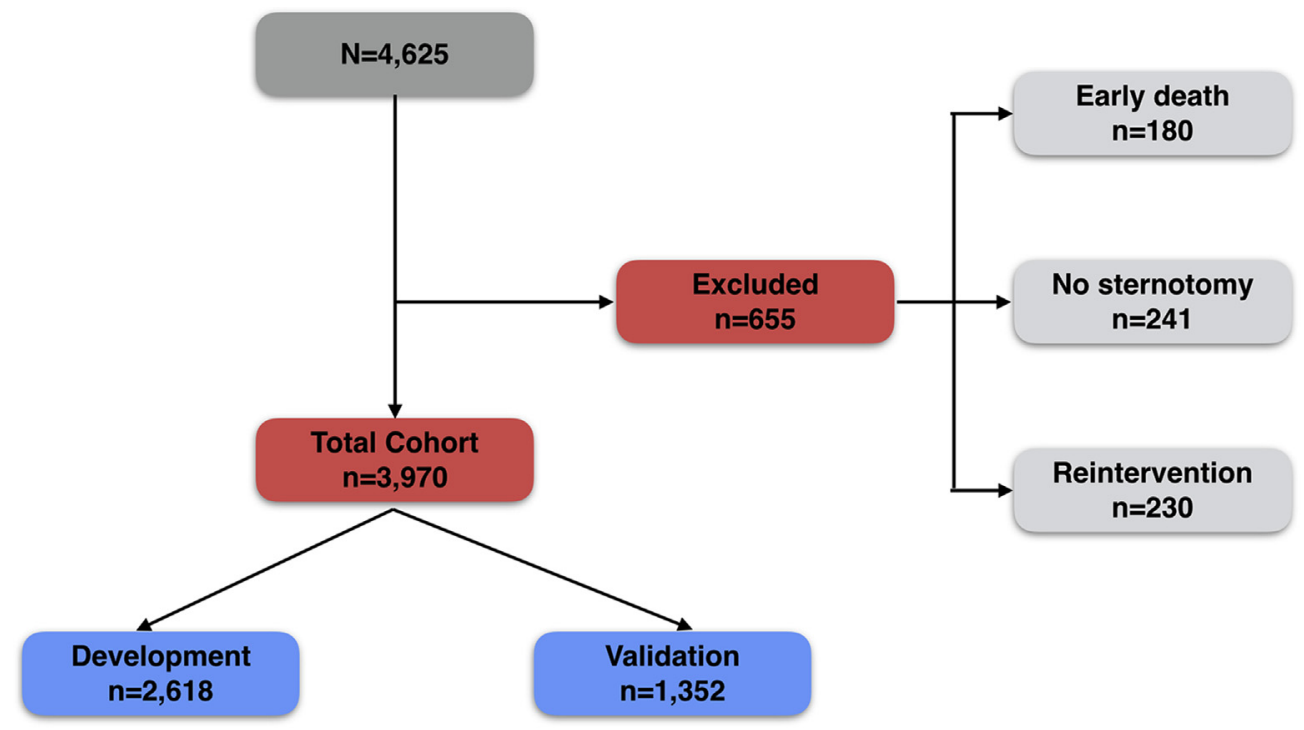

FIGURE 1. Flow diagram of participant recruitment. 
TABLE 1. Patient pre-, intra-, and postoperative characteristics by study cohort

\begin{tabular}{|c|c|c|c|}
\hline Variables & $\begin{array}{c}\text { Whole } \\
\mathbf{N}=\mathbf{3 9 7 0}\end{array}$ & $\frac{\text { Model development }}{\mathrm{n}=\mathbf{2 6 1 8}}$ & $\frac{\text { Model validation }}{n=1352}$ \\
\hline \multicolumn{4}{|l|}{ Preoperative } \\
\hline Age, y, mean (SD) & $66.4(11.7)$ & $66.4(11.9)$ & $66.5(11.8)$ \\
\hline Female sex, n (\%) & $1458(36.7)$ & $968(37)$ & $490(36.2)$ \\
\hline BMI, $\mathrm{kg} / \mathrm{m}^{2}$, mean (SD) & $27.1(4.0)$ & $27.02(4.2)$ & $27.2(3.9)$ \\
\hline Diabetes mellitus, n (\%) & $1138(28.9)$ & $738(28.5)$ & $800(29.8)$ \\
\hline COPD, n $(\%)$ & $380(9.6)$ & $260(10)$ & $120(8.9)$ \\
\hline Antiplatelets, n (\%) & $1538(38.7)$ & $1013(38.7)$ & $525(38.8)$ \\
\hline AdES, mean (IQR) & $6(4-8)$ & $6(4-8)$ & $6(4-8)$ \\
\hline $\log E S$, mean (IQR) & $5.0(2.4-9.8)$ & $4.9(2.4-9.7)$ & $5.1(2.3-9.8)$ \\
\hline Urgent/emergent, $\mathrm{n}(\%)$ & $347(8.8)$ & $225(8.6)$ & $122(9.1)$ \\
\hline \multicolumn{4}{|l|}{ Intraoperative } \\
\hline CBP, n $(\%)$ & $2585(65.1)$ & $1700(64.9)$ & $885(65.5)$ \\
\hline CABG, n $(\%)$ & $1360(34.3)$ & $894(34.1)$ & $466(34.5)$ \\
\hline Valve, n $(\%)$ & $1693(42.6)$ & $1101(42.1)$ & $592(43.8)$ \\
\hline Ascending aorta, $\mathrm{n}(\%)$ & $391(9.8)$ & $258(9.9)$ & $133(9.8)$ \\
\hline Combined, n (\%) & $300(7.6)$ & $209(8)$ & $91(6.7)$ \\
\hline Other, n $(\%)$ & $226(5.7)$ & $156(6)$ & $70(5.2)$ \\
\hline IMA, n (\%) & $1618(40.8)$ & $1069(40.8)$ & 549 (40.6) \\
\hline Bilateral IMA, n (\%) & $269(6.8)$ & $160(6.1)$ & $109(8.1)$ \\
\hline \multicolumn{4}{|l|}{ Postoperative } \\
\hline Emergency reoperation (first $24 \mathrm{~h}$ ) & $233(6)$ & $140(5.3)$ & $93(6.9)$ \\
\hline Prolonged intubation $(>24 \mathrm{~h})$ & $338(9)$ & $219(8.4)$ & $119(8.8)$ \\
\hline Status at discharge: dead, $\mathrm{n}(\%)$ & $202(5.1)$ & $136(5.2)$ & $66(4.9)$ \\
\hline Days of ICU stay, median (IQR) & $1(1-3)$ & $1(1-3)$ & $1(1-3)$ \\
\hline Days of hospital stay, median (IQR) & $8(6-12)$ & $8(6-12)$ & $8(6-12)$ \\
\hline
\end{tabular}

$S D$, Standard deviation; $B M I$, body mass index; COPD, chronic obstructive pulmonary disease; AdES, additive EuroSCORE; IQR, interquartile range; logES, logistic EuroSCORE; $C B P$, cardiopulmonary bypass pump; $C A B G$, coronary artery bypass graft; $I M A$, internal mammary artery; $I C U$, intensive care unit; $I Q R$, interquartile range.

\section{METHODS}

\section{Data Source}

The cardiovascular ICU of the Hospital Clínico San Carlos in Madrid, Spain, provides care for patients who have undergone cardiovascular surgery or suffered a critical cardiac event. The unit's database collects data on 242 variables for all patients who undergo heart surgery. For the present study, we identified data for all patients who had undergone major heart surgery (MHS) from January 2005 to June 2011 and combined these data with those of the patients' clinical records to construct a predictive model for PSM.

\section{Participants}

All consecutive patients admitted to the ICU after MHS aged older than 17 years were included in this study. We excluded patients who died within 4 days of surgery, were operated on without sternotomy, or who were admitted after reoperation for complications during the same admission (Figure 1). The bundle of practices used to prevent SSI in our Cardiovascular Program can be found in Appendix E1. We selected 48 variables from the literature, including demographic, preoperative, intraoperative, and postoperative factors as potential mediastinitis risk factors. The definitions of categorical and continuous variables are those reported for the EuroSCORE. ${ }^{13}$

\section{Outcome}

The outcome of interest was mediastinitis. This was defined as described by the Centers for Disease Control and Prevention as an infection involving tissues and spaces underneath the subcutaneous tissue fulfilling at least 1 of the following criteria: (1) positive culture of mediastinal tissue or fluid; (2) evidence of mediastinitis during operation or histology; and (3) 1 of the following: fever $\left(38.8^{\circ} \mathrm{C}\right)$, chest pain, or sternal instability, as well as either purulent drainage from the mediastinum or mediastinal widening on imaging tests. SSI was monitored during hospital stay and readmissions over 1 year.

\section{Predictors}

The following variables were examined: age, sex, body mass index, hypertension, diabetes, smoking, dyslipidemia, extracardiac arteriopathy, kidney failure, chronic obstructive pulmonary disease (COPD), New York Heart Association classification, left ventricular ejection fraction, recent myocardial infarction, pulmonary hypertension, cardiogenic shock, surgical risk estimated by the logistic EuroSCORE (logES), previous interventions, preoperative stay, antiplatelet and/or anticoagulant agents, type of cardiac surgery (valve, coronary artery bypass grafting [CABG], mixed [CABG plus valve], aortic, other MHS), surgical priority (elective, urgent, or emergent), use of cardiopulmonary bypass (CBP) pump, duration of CBP, ischemia or aortic crossclamping, use of internal mammary artery (IMA) or double IMA, surgical drainage at 24 hours postsurgery, emergent reoperation for bleeding and/or tamponade at 24 hours, duration of mechanical ventilation, prolonged endotracheal intubation ( $>24$ hours), vasopressor support, and length of ICU stay.

\section{Statistical Analysis}

A required sample size of 3529 consecutive patients was calculated for a $95 \%$ confidence interval $(95 \% \mathrm{CI})$ and accuracy of $0.5 \%$ for a $2.4 \%$ probability of mediastinitis. To adjust the multivariate model, we estimated that approximately 10 variables would need to be considered, ie, 100 events 
TABLE 2. Univariate analysis of data from the model development cohort $(n=2618)$

\begin{tabular}{|c|c|c|c|}
\hline Variable & $\begin{array}{c}\text { Mediastinitis } \\
\text { probability } \\
\%(\mathbf{n} / \mathbf{N})\end{array}$ & OR $(95 \%$ CI $)$ & $P$ value \\
\hline \multicolumn{4}{|l|}{ Age, y } \\
\hline$<55$ & $1.42(6 / 416)$ & 1 & .063 \\
\hline $55-64$ & $1.80(11 / 599)$ & $1.27(0.47-3.47)$ & \\
\hline $65-70$ & $1.97(9 / 448)$ & $1.39(0.49-3.95)$ & \\
\hline $71-74$ & $2.28(10 / 429)$ & $1.62(0.58-4.49)$ & \\
\hline $75-80$ & $3.65(19 / 501)$ & $2.63(1.04-6.64)$ & \\
\hline$>80$ & $2.94(5 / 165)$ & $2.1(0.63-6.98)$ & \\
\hline \multicolumn{4}{|l|}{ Age $>70 y$} \\
\hline Yes & $3.0(36 / 1216)$ & $1.75(1.03-2.95)$ & .033 \\
\hline No & $1.7(24 / 1402)$ & & \\
\hline \multicolumn{4}{|l|}{ Sex } \\
\hline Female & $2.5(24 / 968)$ & $0.88(0.52-1.48)$ & .623 \\
\hline Male & $2.2(36 / 1650)$ & 1 & \\
\hline \multicolumn{4}{|l|}{ BMI $>30, \mathrm{~kg} / \mathrm{m}^{2}$} \\
\hline Yes & $3.9(22 / 567)$ & $1.7(1.22-3.54)$ & .006 \\
\hline No & $1.9(38 / 1991)$ & & \\
\hline \multicolumn{4}{|l|}{ Diabetes mellitus } \\
\hline Insulin & $3.1(7 / 227)$ & $0.67(0.30-1.53)$ & .544 \\
\hline OAD & $3.0(13 / 436)$ & $0.42(0.05-3.51)$ & \\
\hline Diet & $1.3(1 / 75)$ & $0.97(0.38-2.46)$ & \\
\hline No diabetes mellitus & $2.1(39 / 1855)$ & 1 & \\
\hline \multicolumn{4}{|l|}{ Hypertension } \\
\hline Yes & $2.8(44 / 1585)$ & $1.91(1.06-3.46)$ & .029 \\
\hline No & $1.5(15 / 1021)$ & & \\
\hline \multicolumn{4}{|c|}{ Peripheral vascular disease } \\
\hline Yes & $2.6(9 / 349)$ & $1.21(0.55-2.31)$ & .744 \\
\hline No & $2.3(51 / 2222)$ & & \\
\hline \multicolumn{4}{|l|}{ COPD } \\
\hline Yes & $4.6(12 / 960)$ & $2.32(1.21-4.42)$ & .009 \\
\hline No & $2.0(45 / 2350)$ & & \\
\hline \multicolumn{4}{|l|}{ Endocarditis } \\
\hline Yes & $4.7(4 / 85)$ & $2.15(0.77-6.19)$ & .131 \\
\hline No & $2.2(56 / 2533)$ & & \\
\hline \multicolumn{4}{|l|}{ Antiplatelets } \\
\hline Yes & $3.0(30 / 1013)$ & $1.6(0.96-2.67)$ & .069 \\
\hline No & $1.9(30 / 1605)$ & & \\
\hline \multicolumn{4}{|l|}{ Kidney failure } \\
\hline Yes & $3.4(32 / 930)$ & $2.10(1.25-3.51)$ & .004 \\
\hline No & $1.7(28 / 1680)$ & & \\
\hline \multicolumn{4}{|l|}{$\mathrm{MI}<90 \mathrm{~d}$} \\
\hline Yes & $1.9(7 / 368)$ & $0.78(0.35-1.73)$ & .53 \\
\hline No & $2.4(51 / 2099)$ & & \\
\hline \multicolumn{4}{|l|}{ Cardiogenic shock } \\
\hline Yes & $1.7(1 / 58)$ & $0.75(0.10-5.53)$ & 1 \\
\hline No & $2.3(58 / 2547)$ & & \\
\hline \multicolumn{4}{|l|}{ Intra-aortic balloon pump } \\
\hline Yes & $2.2(4 / 179)$ & $0.94(0.33-2.62)$ & .903 \\
\hline No & $2.4(54 / 2270)$ & & \\
\hline
\end{tabular}

(Continued)
TABLE 2. Continued

\begin{tabular}{|c|c|c|c|}
\hline Variable & $\begin{array}{c}\text { Mediastinitis } \\
\text { probability } \\
\%(\mathbf{n} / \mathbf{N})\end{array}$ & OR $(95 \%$ CI $)$ & $P$ value \\
\hline Yes & $2.4(11 / 454)$ & $1.06(0.55-2.07)$ & .847 \\
\hline No & $2.3(49 / 2155)$ & & \\
\hline \multicolumn{4}{|l|}{ Severe PHT } \\
\hline Yes & $1.0(3 / 287)$ & $0.42(0.13-1.35)$ & .133 \\
\hline No & $2.5(57 / 2321)$ & & \\
\hline \multicolumn{4}{|l|}{ NYHA } \\
\hline I-II & $2.3(19 / 831)$ & 1 & .701 \\
\hline III & $2.6(39 / 1490)$ & $1.15(0.66-2.0)$ & \\
\hline IV & $1.6(2 / 128)$ & $0.68(0.16-2.95)$ & \\
\hline \multicolumn{4}{|c|}{ Involvement of ascending aorta } \\
\hline Yes & $1.5(3 / 214)$ & $0.58(0.18-1.88)$ & .364 \\
\hline No & $2.4(57 / 2404)$ & 1 & \\
\hline \multicolumn{4}{|c|}{ Previous cardiac surgery } \\
\hline Yes & $2.5(8 / 314)$ & $1.11(0.52-2.36)$ & .783 \\
\hline No & $2.3(52 / 2263)$ & 1 & \\
\hline \multicolumn{4}{|l|}{ Surgery status } \\
\hline Urgent/emergent & $4.0(9 / 225)$ & $0.71(0.39-1.29)$ & .114 \\
\hline Inpatient & $1.7(16 / 928)$ & $1.68(0.80-3.55)$ & \\
\hline Elective outpatient & $2.4(35 / 1449)$ & 1 & \\
\hline \multicolumn{4}{|l|}{ CPB on-pump } \\
\hline Yes & $2.4(41 / 1700)$ & $1.16(0.67-2.02)$ & .577 \\
\hline No & $2.1(19 / 918)$ & & \\
\hline \multicolumn{4}{|c|}{ Perfusion time quartiles, min } \\
\hline 0 (off-pump) & $2.0(19 / 938)$ & 1 & .019 \\
\hline$<55$ & $0.8(3 / 355)$ & $0.39(0.11-1.33)$ & \\
\hline $56-83$ & $2.0(14 / 642)$ & $1.11(0.55-2.23)$ & \\
\hline$>83$ & $3.8(24 / 640)$ & $1.88(1.02-3.47)$ & \\
\hline \multicolumn{4}{|c|}{ Prolonged perfusion time (Q3) } \\
\hline Yes & $3.8(24 / 640)$ & $2.01(1.22-3.47)$ & .006 \\
\hline No & $1.9(36 / 1936)$ & & \\
\hline \multicolumn{4}{|c|}{$\begin{array}{l}\text { Ischemia or aortic crossclamp time, } \\
\text { quartiles, min }\end{array}$} \\
\hline 0 & $2.0(20 / 1000)$ & 1 & .037 \\
\hline$<40$ & $1.3(4 / 317)$ & $0.68(0.22-1.95)$ & \\
\hline $41-63$ & $1.8(12 / 658)$ & $1.04(0.51-2.12)$ & \\
\hline$>64$ & $3.7(24 / 643)$ & $2(1.09-3.68)$ & \\
\hline \multicolumn{4}{|c|}{ Prolonged ischemia time (Q3) } \\
\hline Yes & $3.8(24 / 640)$ & $2.08(1.23-3.52)$ & .005 \\
\hline No & $1.9(36 / 1936)$ & & \\
\hline \multicolumn{4}{|l|}{ Procedure } \\
\hline CABG & $2.0(18 / 894)$ & $1.04(0.38-2.83)$ & .050 \\
\hline Valve & $2.2(24 / 1101)$ & $1.13(0.43-2.98)$ & \\
\hline Aorta & $1.9(5 / 258)$ & 1 & \\
\hline Combined & $5.3(11 / 209)$ & $2.81(0.96-8.22)$ & \\
\hline Others & $1.3(2 / 156)$ & $0.66(0.13-3.43)$ & \\
\hline \multicolumn{4}{|l|}{ No CABG surgery } \\
\hline Yes & $2.4(42 / 1724)$ & $1.21(0.69-2.12)$ & .493 \\
\hline No & $2.0(18 / 894)$ & & \\
\hline Valve surgery & & & \\
\hline
\end{tabular}

(Continued) 
TABLE 2. Continued

\begin{tabular}{|c|c|c|c|}
\hline Variable & $\begin{array}{c}\text { Mediastinitis } \\
\text { probability } \\
\%(\mathbf{n} / \mathbf{N})\end{array}$ & OR $(95 \%$ CI $)$ & $P$ value \\
\hline Yes & $2.6(39 / 1513)$ & $1.36(0.79-2.33)$ & .253 \\
\hline No & $1.9(21 / 1105)$ & & \\
\hline \multicolumn{4}{|l|}{ Aorta surgery } \\
\hline Yes & $1.4(3 / 214)$ & $0.58(0.18-1.88)$ & .364 \\
\hline No & $2.4(57 / 2404)$ & & \\
\hline \multicolumn{4}{|l|}{ IMA use } \\
\hline Yes & $2.8(30 / 1069)$ & $1.46(0.87-2.44)$ & .144 \\
\hline No & $1.9(30 / 1549)$ & & \\
\hline \multicolumn{4}{|l|}{ IMA bilateral use } \\
\hline Yes & $2.5(4 / 160)$ & $1.10(0.39-3.07)$ & .859 \\
\hline No & $2.3(56 / 2458)$ & & \\
\hline \multicolumn{4}{|c|}{ Urgent reoperation } \\
\hline Yes & $9.3(13 / 140)$ & $5.29(2.79-10.03)$ & $<.01$ \\
\hline No & $1.9(47 / 2478)$ & & \\
\hline \multicolumn{4}{|c|}{ Reoperation for bleeding } \\
\hline Yes & $8.9(9 / 101)$ & $4.73(2.26-9.90)$ & $<.001$ \\
\hline No & $2.0(51 / 2517)$ & & \\
\hline \multicolumn{4}{|c|}{ Reoperation for tamponade } \\
\hline Yes & $11.1(5 / 45)$ & $5.72(2.17-15.05)$ & .003 \\
\hline No & $2.1(55 / 2573)$ & & \\
\hline \multicolumn{4}{|c|}{ Vasopressors $>24 \mathrm{~h}$} \\
\hline Yes & $4.7(6 / 129)$ & $2.20(0.93-5.21)$ & .066 \\
\hline No & $2.2(54 / 2489)$ & & \\
\hline \multicolumn{4}{|l|}{ Intubation $>24 \mathrm{~h}$} \\
\hline Yes & $11.0(24 / 219)$ & $8.0(4.72-13.81)$ & $<.001$ \\
\hline No & $1.5(36 / 2399)$ & & \\
\hline
\end{tabular}

$O R$, Odds ratio; $C I$, confidence interval; $B M I$, body mass index; $O A D$, oral antidiabetics; $C O P D$, chronic obstructive pulmonary disease; $M I$, myocardial infarction; $P H T$, pulmonary hypertension; $N Y H A$, New York Heart Association; $C P B$, cardiopulmonary bypass; $Q$, quartile; $C A B G$, coronary artery bypass graft; $I M A$, internal mammary artery.

needed to avoid overdispersion. All available data were included without applying criteria for missing data.

Qualitative variables are presented as their frequencies and quantitative data as the mean and standard deviation or median and interquartile range, as appropriate. The study cohort was randomly divided into 2 groups: two thirds to develop the predictive model (development cohort) and one third for its validation (validation cohort).

The homogeneous distribution of both cohorts was assessed with the $\chi^{2}$ test and Student $t$ test under the assumption of normality, and the median test for variables showing a skewed distribution. Univariate analysis was performed for qualitative variables and reported as odds ratios (OR) with $95 \%$ CI. For quantitative variables, ORs were estimated using a univariate logistic regression model, and receiver operating characteristic (ROC) curves were constructed and divided by quartiles to check for linearity and for categorization. Logistic regression models were adjusted for pre-, intra-, and postoperative variables by backward stepwise regression based on the maximum likelihood estimators. The likelihood ratio and its significance were calculated for each variable according to criteria for entry $(P<.05)$ and removal $(P>.10)$. We selected risk factors showing a $P<.10$ in the univariate analysis or that were clinically relevant. Possible interactions were evaluated with the introduction of multiplicative terms. Discriminative capacity was assessed by the area under the ROC curve
(AUROC) and its 95\% CI. Sensitivity was defined as the capacity of the model to detect infection and specificity as its capacity to rule out infection. The model was calibrated by comparing predicted versus observed probabilities after their calculation from the adjusted model coefficients. The Hosmer-Lemeshow test was used for model goodness-of-fit. The model with the greatest discriminative power, good calibration, viable capacity, and meeting the principle of parsimony (explaining the maximum variability outcome variable with the smallest number of parameters included) was selected.

Med-Score 24 was obtained from the point estimate for each variable using the beta-exponents of the final model. Predicted and observed probabilities were compared. We calculated the AUROC predicted by MedScore 24 in the validation population and then applied Med-Score 24 and the selected scores to the whole cohort. Agreement of risk stratification was evaluated with the weighted Kappa index. AUROCs of the scores were compared with the nonparametric ROC Mann-Whitney $U$ test. $^{27}$ Lastly, Med-Score 24 was validated in a prospective cohort from June 2011 to December 2015.

In all cases, the distribution of the variable was checked against theoretical models and the assumption of homogeneity of variance tested. In all hypothesis tests the null hypothesis with a type I error or $\alpha$ error $<0.05$ was rejected. The statistical packages used for all tests were SPSS 15.0 (SPSS Inc, Chicago, Ill) and STATA 11.0 (StataCorp LLC, College Station, Tex). The study protocol was approved by our local Ethics Committee. The manuscript was drafted following the TRIPOD statement. ${ }^{28}$

\section{RESULTS \\ Participants}

In total, 4625 surgeries were performed from January 2005 to June 2011, 3970 of which fulfilled our inclusion criteria. Of the 3970 heart surgery patients, two thirds were randomly assigned to the predictive model development group $(\mathrm{n}=2618)$ and the remaining one third $(\mathrm{n}=1352)$ to the model validation group (Figure 1$)$.

Mediastinitis developed after 94 surgical interventions $(2.36 \%)$. The main characteristics of the study participants (Table 1) were homogeneous in those developing PSM and those not, and no significant period effect was detected (Tables E1 and E2). Patients developing mediastinitis showed a complicated clinical course with a significantly greater incidence of complications requiring readmission to the ICU in some cases associated with a prolonged median (interquartile range) ICU length of stay of 5 (2-31) versus 1 (1-3) days and hospital length of stay of 50.5 (34.2-75.2) versus 5.5 (2-31) days, compared with patients not developing mediastinitis, respectively. These patients also more frequently needed early hospital readmission within 30 days than patients not developing mediastinitis ( $22.4 \%$ of patients vs $1.7 \%$ ). Mortality was also significantly greater in patients developing mediastinitis: $27.7 \%$ versus $5.4 \%$ (Table E3) $(P<.001$ ).

\section{Model Development}

Univariate analysis of the model development cohort is provided in Table 2. The following risk factors were included in the models adjusted for the development cohort: the preoperative factors age $>70$ years, hypertension, COPD, kidney failure, antiplatelet therapy, body mass index 
TABLE 3. Logistic regression models adjusted for each defined period in the model development cohort and final predictive model and scoring system $(\mathbf{n}=\mathbf{2 6 1 8})$

\begin{tabular}{|c|c|c|c|c|c|}
\hline \multirow[b]{2}{*}{ Risk factor } & \multirow{2}{*}{$\frac{\text { Preoperative model }}{\text { OR }(95 \% \mathrm{CI})}$} & \multirow{2}{*}{$\frac{\text { Pre }+ \text { intraoperative model }}{\text { OR }(95 \% \text { CI })}$} & \multirow{2}{*}{$\frac{\text { Overall model }}{\text { OR }(95 \% \mathbf{C I})}$} & \multicolumn{2}{|c|}{ Scoring system } \\
\hline & & & & $\beta$ & Points \\
\hline Age $>70 y$ & $1.02(1.00-1.05)$ & $1.02(0.99-1.05)$ & $2.26(1.25-4.08)$ & 0.81 & 2 \\
\hline COPD & $2.01(1.05-3.87)$ & $2.07(1.07-4.00)$ & $2.41(1.18-4.89)$ & 0.88 & 2 \\
\hline Kidney failure & $1.85(1.08-3.16)$ & $1.79(1.05-3.07)$ & & & \\
\hline Antiplatelets & $1.56(0.93-2.62)$ & $2.00(1.15-3.46)$ & $2.13(1.17-3.89)$ & 0.81 & 2 \\
\hline BMI $>30, \mathrm{~kg} / \mathrm{m}^{2}$ & $1.96(1.14-3.35)$ & $2.05(1.19-3.53)$ & $2.26(1.23-4.15)$ & 0.7 & 2 \\
\hline Perfusion time Q3 & & $2.68(1.53-4.71)$ & & & \\
\hline Ischemia time Q3 & & & $2.92(1.59-5.38)$ & 1.29 & 3 \\
\hline Emergent reoperation & & & $3.85(1.83-8.11)$ & 1.34 & 4 \\
\hline Prolonged intubation & & & $3.63(1.90-6.94)$ & 1.29 & 4 \\
\hline Constant & & & & -5.69 & \\
\hline AUROC OR $(95 \%$ CI $)$ & $0.67(0.60-0.74)$ & $0.72(0.65-0.80)$ & $0.80(0.74-0.86)$ & $0.77(0.70-0.83)$ & \\
\hline Sensitivity $(\%)$ & 76 & 68 & 77 & & \\
\hline Specificity (\%) & 52 & 58 & 72 & & \\
\hline
\end{tabular}

$O R$, Odds ratio; $C I$, confidence interval; $\beta$, beta-exponents; $C O P D$, chronic obstructive pulmonary disease; $B M I$, body mass index; $Q$, quartile; $A U R O C$, area under the receiver operating characteristic curve.

$>30 \mathrm{~kg} / \mathrm{m}^{2}$, and $\log \mathrm{ES}$; the intraoperative factors mixed procedures, emergency surgery, use of IMA, third quartile of CPB time ( $>83$ minutes) and third quartile of ischemia time ( $>64$ minutes); and the postoperative factors vasopressors, emergency reoperation for bleeding or tamponade, and intubation $>24$ hours. Three models were constructed sequentially. We then selected the model with the greatest discriminative capacity (AUROC 0.80; 95\% CI, 0.740.86 ), sensitivity, and specificity as a potentially feasible model. Thus, the final model used to develop the risk score consisted of 7 variables with independent predictive capacity (4 preoperative, 1 intraoperative, and 2 postoperative).

\section{Risk Score}

The scoring system was based on the relative weights obtained by rounding ORs assigning: 2 points for age $>70$ years, COPD, obesity, and antiplatelet therapy; 3 points for ischemia duration $>60$ minutes; and 4 points for emergency reoperation and prolonged intubation to give a range of 0 to 19 points (Table 3). Goodness-of-fit determined in the Hosmer-Lemeshow test was $P=.46$.

We also defined 3 risk levels according to individual scores: low (0-5 points), intermediate (6-9 points) (OR, 7.24; 95\% CI, 4.05-12.93), and high ( $\geq 10$ points) (OR, 17.58 ; 95\% CI, 7.84-39.40). Mediastinitis risk levels in the model development cohort were low in 2057 patients $(78.5 \%)$, intermediate in $490(18.7 \%)$, and high in 71 $(2.7 \%)$. The predicted and observed incidences of the 3 risk levels were not significantly different (Figure 2, A). The discriminatory power of Med-Score 24 (AUROC, $0.77 ; 95 \%$ CI, $0.70-0.83$ ) was lower than in the final model. This difference was not significant $(P=.715)$. Figure 3 and
Tables E4 to E6, show score correlations with predicted risk.

\section{Score Validation}

In the model validation cohort, Med-Score 24 classified 1050 patients $(77.6 \%)$ as having a low risk, $257(19 \%)$ an intermediate risk, and $45(3 \%)$ a high risk of developing mediastinitis. Figure 2, B, shows Med-Score 24 predicted and observed incidences of mediastinitis among patients in the 3 risk groups.

Med-Score 24 was also validated prospectively in a cohort of 2516 patients (June 2011-December 2015). Forty-three of these patients developed mediastinitis $(1.7 \%)$. The discriminative and stratification capacity of Med-Score 24 proved excellent. The AUROC was 0.76 (95\% CI, 0.69-0.82), and the numbers of patients developing mediastinitis were $12(0.7 \%)$ of 1798 patients $(71.5 \%)$ classified as showing a low risk (used as reference), $21(3.5 \%)$ of 598 patients $(23 \%)$ showing an intermediate risk (relative risk, 5.4; 95\% CI, 2.6-11.1), and 10 $(8.5 \%)$ of 120 patients $(4.7 \%)$ showing a high risk (relative risk, $13.5 ; \quad 95 \%$ CI, 5.7-32.2). Hosmer-Lemeshow goodness-of-fit was $P=.999$.

\section{Other Risk Scores}

To compare the discriminatory power of Med-Score 24 with those of the scores of $\log E S$ and Society of Thoracic Surgeons (STS), ${ }^{1}$ the scoring systems were applied to the whole patient cohort. Poor risk stratification agreement with Med-Score 24 was detected: $\kappa 0.12$ (95\% CI, 0.11 $0.13)$ for preoperative STS score, $\kappa 0.13$ (95\% CI, 0.12$0.15)$ for the combined STS score, and $\kappa 0.121(95 \% \mathrm{CI}$, 

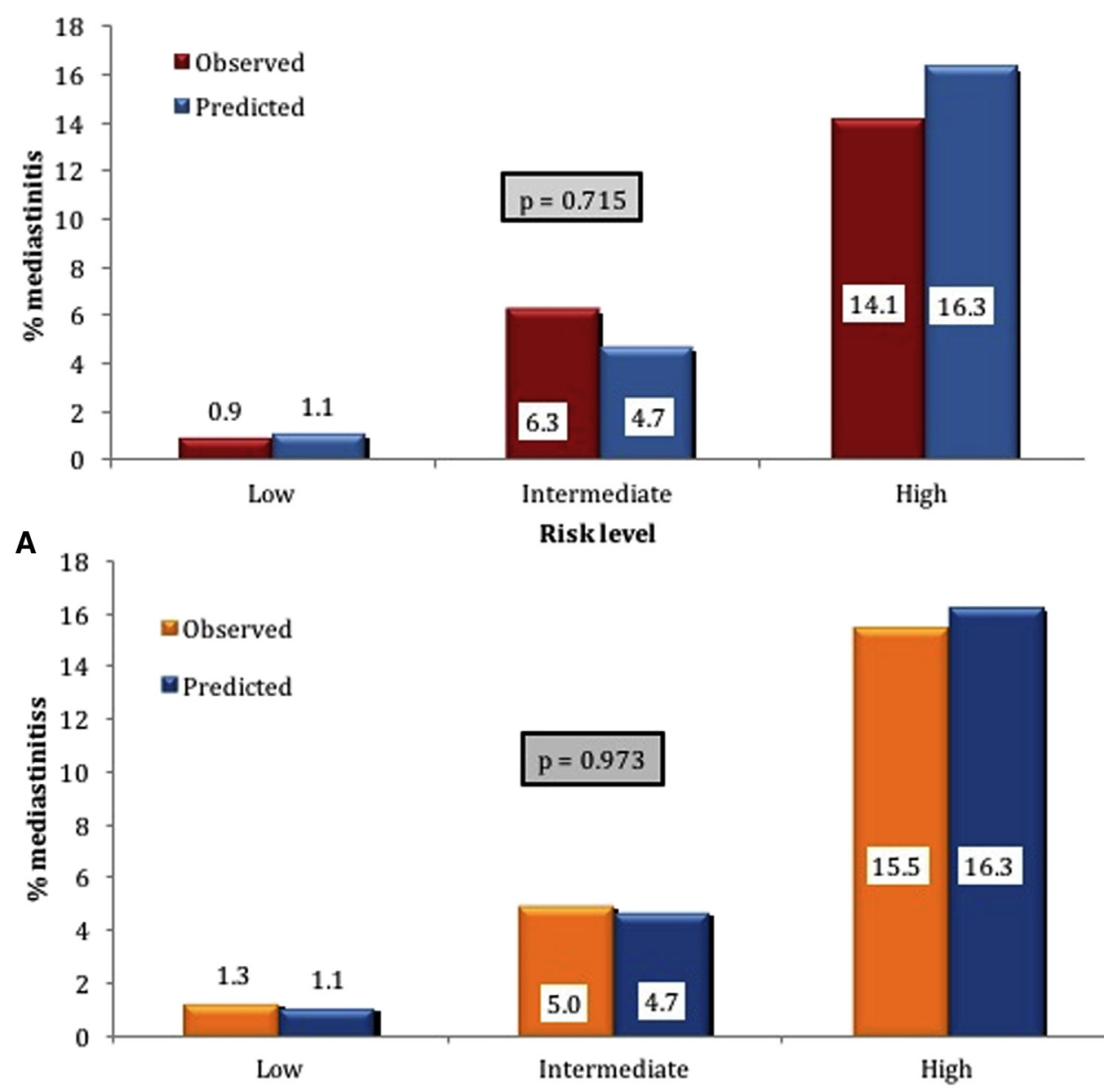

Risk level

B

FIGURE 2. Med-Score 24 observed and predicted probability distributions in the model development (A) $(n=2658)$ and model validation $(B)(n=1352)$ cohorts.

$0.10-0.14)$ for the $\log E S$. The AUROCs for STS $(0.63 ; 95 \%$ CI, 0.551-0.695) and $\log E S(0.55 ; 95 \%$ CI, 0.492-0.623) indicated the significantly lower discriminative power of these scores $(P=.014$ and $P<.001$, respectively) than Med-Score 24 (0.79; 95\% CI, 0.73-0.86) (Figure 4).

\section{DISCUSSION}

The findings of this study indicate that a risk level for PSM can be obtained in a patient undergoing heart surgery within 24 hours of admission to the ICU on the basis of routinely collected and easily available clinical information. The scoring system developed, Med-Score 24, emerged as a simple tool for classifying patients undergoing MHS according to their risk-low, intermediate, or highof subsequently developing mediastinitis. The predictive power of Med-Score 24 was significantly greater than those of the well-established risk scoring systems STS and logES.

The patient cohorts used here to develop and validate our model were homogeneous and sufficiently large to provide adequate statistical power. The final model was validated, confirming its good discriminatory power in both a historical and prospective cohort. The lower AUROC observed in the model validation cohort is likely explained by the low incidence of the outcome measure, although the model still showed good stratification capacity. The risk of selection bias due to confounders was minimized by including all consecutive patients undergoing heart surgery over a 7-year period.

As in our study, models including only preoperative variables seem to show less discriminatory power than those also based on perioperative variables. ${ }^{21,29-32}$ Preoperative variables, like age, obesity, and COPD, have been identified as risk factors for PSM in other surgical risk scores. $^{3,4,22,25,33,34}$ In contrast, the use of antiplatelet agents has been rarely assessed as a risk factor for mediastinitis. ${ }^{33}$ In our study, the use of any preoperative antiplatelet drug emerged as an independent risk factor, doubling the risk of a patient developing mediastinitis. In 


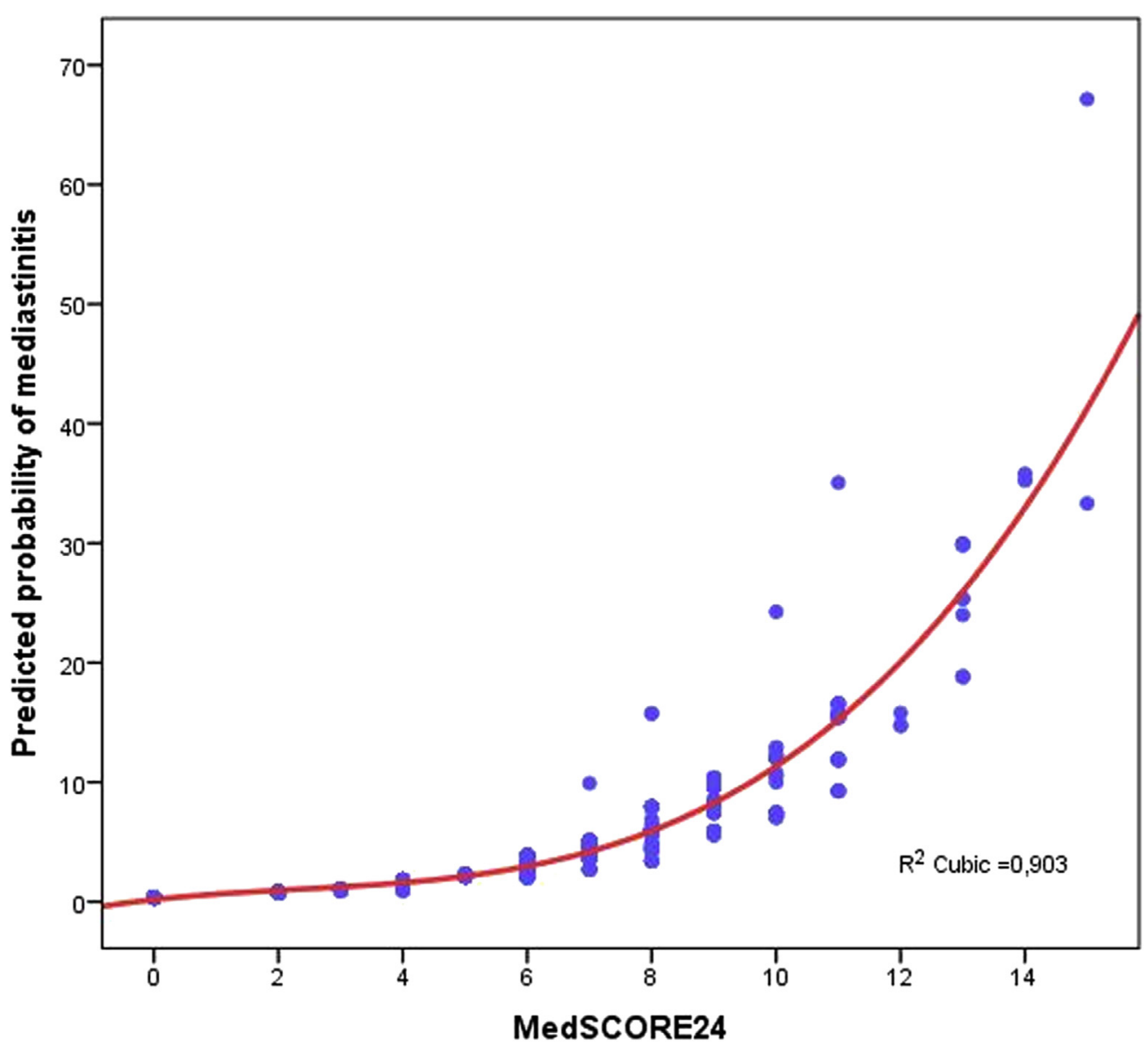

FIGURE 3. Score correlations with predicted risk.

line with our findings, antiplatelet agents not only prevent hemostasis but also cause immune response alterations. ${ }^{34}$

In contrast, other frequently identified risk factors such as diabetes mellitus, preoperative length of stay, or use of IMA could not be confirmed in our study. We hypothesize that our perioperative protocol for glycemic control could reduce the risk of SSI in patients with diabetes as also suggested by others. ${ }^{35}$ Although preoperative length of stay did not emerge as an independent risk factor for mediastinitis in our study, our analysis of this variable may have been biased because the database used only collects admission data for our hospital, and some patients were referred from other centers for surgery.

The use of IMA has also been shown to be a risk factor for mediastinitis. In these studies, however, MHS was conducted under CBP, whereas in our cohort CABG was mostly offpump, possibly reducing ischemia time. Our low incidence of mediastinitis in patients undergoing IMA grafting could be explained by artery harvesting by skeletonization. This technique serves to preserve the rest of the vascular bundle, thus maintaining sternal irrigation and reducing the risk of infection. $^{10,12}$
The sensitivity of the model for the outcome variable was high, since all SSIs developing during hospital stay, as well as those diagnosed after discharge, were recorded. The homogeneous diagnostic criteria defined determined that the model's specificity was also good. We used Centers for Disease Control and Prevention criteria to define PSM. In some studies, mediastinitis is not clearly defined or the authors' own criteria are used. Further, sometimes both superficial and deep would infections are included in prediction models. ${ }^{4,17,25,26}$ Besides their different incidence, these 2 infections differ in their morbidity and mortality. In the 2005 STS score, ${ }^{1}$ the main outcome was SSI or sepsis of any origin, implying that the risk of developing mediastinitis is similar to that of developing other postoperative infections.

The limitations of our study are mainly those related to its single-center nature. Thus, although the predictive model developed showed excellent discriminatory power, it was only validated at our center. Risk factors identified at 1 institution may play a different role in another patient setting due to differences in preoperative management, surgical 


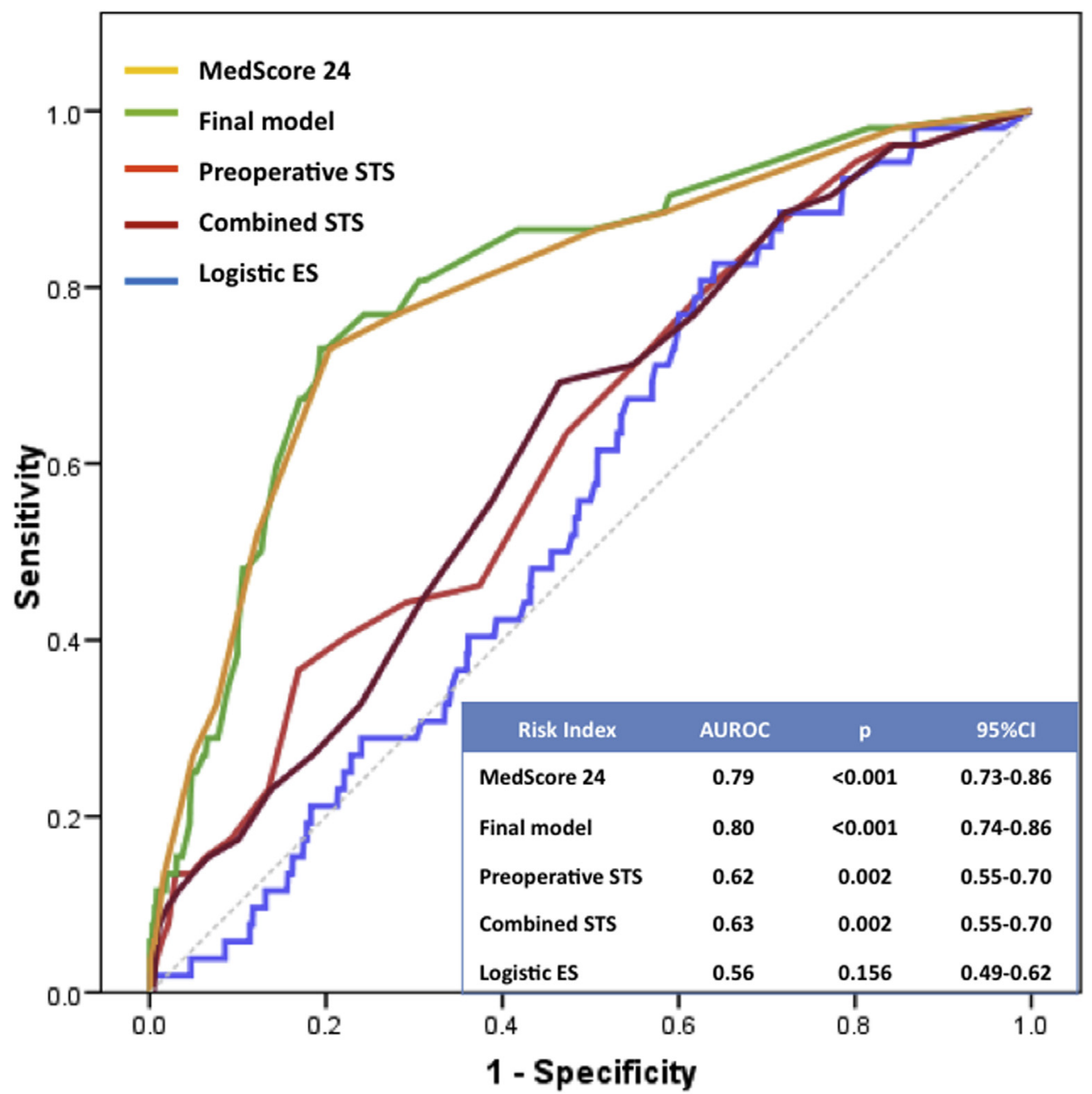

FIGURE 4. Discriminating power of risk scoring systems in the whole cohort $(\mathrm{n}=3970)$. STS, Society of Thoracic Surgeons; ES, EuroSCORE; AUROC, area under the receiver operating characteristic curve; $C I$, confidence interval.

protocols, and postoperative care. Also, our patient population was relatively homogenous compared with cohorts in other regions of the world, ie, those showing greater variation in terms of patient race and ethnicity or prevalence of obesity. The Med-Score 24 thus requires external validation. Our predictive model is based on well-defined, measurable, and easily accessible variables and this will allow for its easy validation at other centers. Effectively, the good predictive power of the model suggests its results may be fairly generalizable. Moreover, its 7 variables can be obtained at the patient's bedside without the need for further tests, calculations, or subjective interpretation. Further, we should mention that our model shows the characteristic features of a reliable and easily extrapolatable predictive model, as we included all variables potentially associated with mediastinitis reported in the literature.

Another potential limitation of our study is that other contributing risk factors for SSI such as noncompliance with preventive strategies were not considered. However, we can nevertheless assume a stable and good measure of compliance because of the existence of detailed protocols for the prevention of mediastinitis, an experienced surgical team, and well-established perioperative care measures.

Finally, when STS and logES scores were assigned to our whole patient cohort, a different distribution of risk levels was observed compared with the use of Med-Score 24. Resultant AUROCs indicated a significantly lower predictive power for mediastinitis of these established scoring systems. In other studies, these models have shown suboptimal performance as they only consider preoperative variables, ${ }^{17-20,23-26}$ as noted here for our preoperative model. The $\operatorname{logES}$ model has proved its good discriminatory capacity for superficial SSI, but this capacity was found to be suboptimal for deep SSI, ${ }^{26}$ as when used in our cohort. In contrast, a greater cumulative EuroSCORE has been linked to a greater risk of SSI. ${ }^{35}$ Such contrasting findings could be related to differences in definitions, follow-up duration, missing data, surgical procedures, geographic 
location, and study period (30 days, 60 days, or 1 year after surgery as in our study).

Our results are in agreement with the opinions expressed by some authors, who consider that EuroSCORE-a well-validated score for predicting mortality after cardiac surgery-is not a good predictor of mediastinitis. ${ }^{35}$ Although comparing the validity and predictive power of large databases is challenging, we used the robust ROC analysis method to confirm the better performance of Med-Score 24 over STS and $\operatorname{logES}$ for this purpose. We did not compare our scoring system to more recent scores, for instance EuroSCORE II and the latest STS scores, ${ }^{17-20}$ because they use variables not prospectively collected in our historical database.

\section{CONCLUSIONS}

The predictive model proposed here emerged as a valid, simple tool to detect within 24 hours of ICU admission the risk of PSM. In our cohort, Med-Score 24 served to stratify patients according to their risk level such that moderate- to high-risk patients could be subjected to prevention measures and increased alertness during their postoperative care. Med-Score 24 requires external validation at different centers. Future work should also be targeted at assessing the clinical impacts of implementing Med-Score 24.

\section{Conflict of Interest Statement}

Authors have nothing to disclose with regard to commercial support.

The authors thank Ana Burton for editorial assistance.

\section{References}

1. Fowler VG, O'Brien SM, Muhlbaier LH, Corey GR, Ferguson TB, Peterson ED. Clinical predictors of major infections after cardiac surgery. Circulation. 2005; 112(9 suppl):I358-65.

2. Bouza E, Hortal J, Muñoz P, Pérez MJ, Riesgo MJ, Hiesmayr M. Infections following major heart surgery in European intensive care units: there is room for improvement (ESGNI 007 Study). J Hosp Infect. 2006;63:399-405.

3. Calderwood MS, Kleinman K, Soumerai SB, Jin R, Gay C, Piatt R, et al. Impact of Medicare's payment policy on mediastinitis following coronary artery bypass graft surgery in US hospitals. Infect Control Hosp Epidemiol. 2014;35:144-51.

4. Risnes I, Abdelnoor M, Almdahl SM, Svennevig JL. Mediastinitis after coronary artery bypass grafting risk factors and long-term survival. Ann Thorac Surg. 2010;89:1502-9.

5. Rahmanian PB, Adams DH, Castillo JG, Carpentier A, Filsoufi F. Predicting hospital mortality and analysis of long-term survival after major noncardiac complications in cardiac surgery patients. Ann Thorac Surg. 2010;90:1221-9.

6. Toumpoulis IK, Anagnostopoulos CE, Derose JJ Jr, Swistel DG. The impact of deep sternal wound infection on long-term survival after coronary artery bypass grafting. Chest. 2005;127:464-71.

7. Braxton JH, Marrin CA, McGrath PD, Morton JR, Norotsky M, Charlesworth DC, et al. 10-year follow-up of patients with and without mediastinitis. Semin Thorac Cardiovasc Surg. 2004;16:70-6.

8. Speir AM, Kasirajan V, Barnett SD, Fonner E Jr. Additive costs of postoperative complications for isolated coronary artery bypass grafting patients in Virginia. Ann Thorac Surg. 2009;88:40-5; discussion 45-6.

9. Zimlichman E, Henderson D, Tamir O, Franz C, Song P, Yamin CK, et al. Health care-associated infections: a meta-analysis of costs and financial impact on the US health care system. JAMA Intern Med. 2013;173:2039-46.
10. Hirose H, Inaba H, Noguchi C, Tambara K, Yamamoto T, Yamasaki M, et al. EuroSCORE predicts postoperative mortality, certain morbidities, and recovery time. Interact Cardiovasc Thorac Surg. 2009;9:613-7.

11. Roques F, Michel P, Goldstone AR, Nashef SA. The logistic EuroSCORE. Eur Heart J. 2003;24:881-2.

12. Head SJ, Osnabrugge RL, Howell NJ, Freemantle N, Bridgewater B, Pagano D, et al. A systematic review of risk prediction in adult cardiac surgery: considerations for future model development. Eur J Cardiothorac Surg. 2013; 43:e121-9.

13. Roques F, Nashef SA, Michel P, Gauducheau E, de Vincentiis C, Baudet E, et al. Risk factors and outcome in European cardiac surgery: analysis of the EuroSCORE multinational database of 19030 patients. Eur J Cardiothorac Surg. 1999; 15:816-22; discussion 822-3.

14. Nashef SA, Roques F, Michel P, Gauducheau E, Lemeshow S, Salamon R. European system for cardiac operative risk evaluation (EuroSCORE). Eur J Cardiothorac Surg. 1999;16:9-13.

15. National Nosocomial Infections Surveillance System. National Nosocomial Infections Surveillance (NNIS) System Report, data summary from January 1992 through June 2004, issued October 2004. Am J Infect Control. 2004;32: $470-85$.

16. Berrios-Torres SI, Mu Y, Edwards JR, Horan TC, Fridkin SK. Improved risk adjustment in public reporting: coronary artery bypass graft surgical site infections. Infect Control Hosp Epidemiol. 2012;33:463-9.

17. Shahian DM, Edwards FH. The Society of Thoracic Surgeons 2008 cardiac surgery risk models: introduction. Ann Thorac Surg. 2009;88(1 suppl):S1.

18. Shahian DM, O'Brien SM, Filardo G, Ferraris VA, Haan CK, Rich JB, et al. The Society of Thoracic Surgeons 2008 cardiac surgery risk models: part $1 \kappa$ coronary artery bypass grafting surgery. Ann Thorac Surg. 2009;88(1 suppl):S2-22.

19. O'Brien SM, Shahian DM, Filardo G, Ferraris VA, Haan CK, Rich JB, et al. The Society of Thoracic Surgeons 2008 cardiac surgery risk models: part 2-isolated valve surgery. Ann Thorac Surg. 2009;88(1 suppl): S23-42.

20. Shahian DM, O'Brien SM, Filardo G, Ferraris VA, Haan CK, Rich JB, et al. The Society of Thoracic Surgeons 2008 cardiac surgery risk models: part 3-valve plus coronary artery bypass grafting surgery. Ann Thorac Surg. 2009;88(1 suppl):S43-62.

21. Kohli M, Yuan L, Escobar M, David T, Gillis G, Comm B, et al. A risk index for sternal surgical wound infection after cardiovascular surgery. Infect Control Hosp Epidemiol. 2003;24:17-25.

22. Friedman ND, Bull AL, Russo PL, Leder K, Reid C, Billah B, et al. An alternative scoring system to predict risk for surgical site infection complicating coronary artery bypass graft surgery. Infect Control Hosp Epidemiol. 2007;28: $1162-8$.

23. Magedanz EH, Bodanese LC, Guaragna JC, Albuquerque LC, Martins V, Minossi SD, et al. Risk score elaboration for mediastinitis after coronary artery bypass grafting. Rev Bras Cir Cardiovasc. 2010;25:154-9.

24. Wang TK, Choi DH, Haydock D, Gamble G, Stewart R, Ruygrok P. Comparison of risk scores for prediction of complications following aortic valve replacement. Heart Lung Circ. 2015;24:595-601.

25. Ariyaratnam P, Bland M, Loubani M. Risk factors and mortality associated with deep sternal wound infections following coronary bypass surgery with or without concomitant procedures in a UK population: a basis for a new risk model? Interact Cardiovasc Thorac Surg. 2010;11:543-6.

26. Paul M, Raz A, Leibovici L, Madar H, Holinger R, Rubinovitch B. Sternal wound infection after coronary artery bypass graft surgery: validation of existing risk scores. J Thorac Cardiovasc Surg. 2007;133:397-403.

27. DeLong ER, DeLong DM, Clarke-Pearson DL. Comparing the areas under two or more correlated receiver operating characteristic curves: a nonparametric approach. Biometrics. 1988;44:837-45.

28. Collins GS, Reitsma JB, Altman DG, Moons KG, Group T. Transparent reporting of a multivariable prediction model for individual prognosis or diagnosis (TRIPOD): the TRIPOD statement. The TRIPOD Group. Circulation. 2015; 131:211-9.

29. Filsoufi F, Castillo JG, Rahmanian PB, Broumand SR, Silvay G, Carpentier A, et al. Epidemiology of deep sternal wound infection in cardiac surgery. J Cardiothorac Vasc Anesth. 2009;23:488-94.

30. Ridderstolpe L, Gill H, Granfeldt H, Ahlfeldt H, Rutberg H. Superficial and deep sternal wound complications: incidence, risk factors and mortality. Eur J Cardiothorac Surg. 2001;20:1168-75. 
31. Lu JC, Grayson AD, Jha P, Srinivasan AK, Fabri BM. Risk factors for sternal wound infection and mid-term survival following coronary artery bypass surgery. Eur J Cardiothorac Surg. 2003;23:943-9.

32. Cayci C, Russo M, Cheema FH, Martens T, Ozcan V, Argenziano M, et al. Risk analysis of deep sternal wound infections and their impact on long-term survival: a propensity analysis. Ann Plast Surg. 2008;61: 294-301.

33. Celik S, Kirbas A, Gurer O, Yildiz Y, Isik O. Sternal dehiscence in patients with moderate and severe chronic obstructive pulmonary disease undergoing cardiac surgery: the value of supportive thorax vests. J Thorac Cardiovasc Surg. 2011; 141:1398-402.
34. Blasco-Colmenares E, Perl TM, Guallar E, Baumgartner WA, Conte JV, Alejo D et al. Aspirin plus clopidogrel and risk of infection after coronary artery bypass surgery. Arch Intern Med. 2009;169:788-96.

35. Lazar HL, Salm TV, Engelman R, Orgill D, Gordon S. Prevention and management of sternal wound infections. J Thorac Cardiovasc Surg. 2016;152:962-72.

Key Words: poststernotomy mediastinitis, risk score, surgical site infection, postoperative cardiac surgery complications, predictive model 
APPENDIX E1. SURGICAL-SITE INFECTION PREVENTION BUNDLE CURRENTLY USED IN

THE CARDIOVASCULAR PROGRAM AT THE HOSPITAL CLINICO SAN CARLOS, MADRID, SPAIN

- Chlorhexidine bathing or showering of the patient the night before surgery

- Hospital-wide hand hygiene campaign with regular auditing

- Perioperative decolonization with a combination of oral chlorhexidine and nasal mupirocin
- Hair removal outside the operating room using an electric razor

- Antimicrobial prophylaxis: cefazolin 30 to 60 minutes or vancomycin + levofloxacin (allergic or high risk of methicillin-resistant Staphylococcus aureus) 2 hours before incision. Discontinue agent within 24 hours after surgery

- Perioperative control of blood glucose $(<180 \mathrm{mg} / \mathrm{dL})$

- Bone wax should be avoided

- External chest support vest

- Surveillance for surgical-site infection 
TABLE E1. Patient pre-, intra-, and postoperative characteristics by study cohort

\begin{tabular}{|c|c|c|c|c|c|c|}
\hline \multirow[b]{2}{*}{ Variables } & \multicolumn{2}{|c|}{$\begin{array}{c}\text { Whole cohort } \\
\mathbf{N}=\mathbf{3 9 7 0}\end{array}$} & \multicolumn{2}{|c|}{$\begin{array}{c}\text { Model development } \\
\mathbf{n}=\mathbf{2 6 1 8}\end{array}$} & \multicolumn{2}{|c|}{$\begin{array}{c}\text { Model validation } \\
\mathbf{n}=\mathbf{1 3 5 2} \\
\end{array}$} \\
\hline & $\mathbf{n}$ & $\%$ & $\mathbf{n}$ & $\%$ & $\mathbf{n}$ & $\%$ \\
\hline \multicolumn{7}{|l|}{ Preoperative variables } \\
\hline Age, y, mean (SD) & $66.4(11.7)$ & & $66.4(11.9)$ & & $66.5(11.8)$ & \\
\hline \multicolumn{7}{|l|}{ Age, $y$, range } \\
\hline$<55$ & 634 & 16 & 422 & 16.1 & 212 & 15.7 \\
\hline $55-64$ & 934 & 23.5 & 610 & 23.3 & 324 & 24 \\
\hline $65-70$ & 704 & 17.7 & 457 & 17.5 & 247 & 18.3 \\
\hline $71-74$ & 638 & 16.1 & 439 & 16.8 & 199 & 14.7 \\
\hline $75-80$ & 803 & 20.2 & 520 & 19.9 & 283 & 20.9 \\
\hline$>80$ & 257 & 6.5 & 170 & 6.5 & 87 & 6.4 \\
\hline \multicolumn{7}{|l|}{ Sex } \\
\hline Female & 1458 & 36.7 & 968 & 37 & 490 & 36.2 \\
\hline BMI, $\mathrm{kg} / \mathrm{m}^{2}$, mean (SD) & $27.1(4.0)$ & & $27.02(4.2)$ & & $27.2(3.9)$ & \\
\hline \multicolumn{7}{|l|}{$\mathrm{BMI}$ range } \\
\hline$<20$ & 108 & 2.8 & 87 & 2.8 & 21 & 1.6 \\
\hline $20-29$ & 2903 & 74.7 & 1905 & 74.7 & 998 & 75.1 \\
\hline $30-35$ & 803 & 20.7 & 519 & 20.7 & 284 & 21.4 \\
\hline$>35$ & 74 & 1.9 & 48 & 1.9 & 26 & 2 \\
\hline \multicolumn{7}{|l|}{ Smoking } \\
\hline No & 2293 & 58,3 & 1529 & 59.0 & 764 & 57.1 \\
\hline Previous history & 1164 & 29.6 & 754 & 29.1 & 410 & 30.6 \\
\hline Current & 473 & 12 & 308 & 11.9 & 165 & 12.3 \\
\hline \multicolumn{7}{|l|}{ Diabetes mellitus } \\
\hline No & 2799 & 71.1 & 1855 & 71.5 & 944 & 70.2 \\
\hline Diet only & 115 & 2.9 & 75 & 2.9 & 40 & 3 \\
\hline Oral antidiabetics & 666 & 16.9 & 436 & 16.8 & 230 & 17.1 \\
\hline Insulin & 357 & 9.1 & 227 & 8.8 & 130 & 9.7 \\
\hline Hypertension & 2448 & 61.9 & 1585 & 60.8 & 863 & 63.9 \\
\hline Dyslipidemia & 2060 & 52.8 & 1337 & 51.9 & 723 & 54.3 \\
\hline Peripheral vascular disease & 528 & 13.5 & 349 & 13.6 & 179 & 13.4 \\
\hline COPD & 380 & 9.6 & 260 & 10 & 120 & 8.9 \\
\hline Kidney failure & 1456 & 36.8 & 930 & 35.6 & 526 & 38.9 \\
\hline Preoperative $\mathrm{Hb}, \mathrm{g} / \mathrm{dL}$, mean (SD) & $13.4(3.1)$ & & $13.4(3.2)$ & & $13.3(2.7)$ & \\
\hline Ejection fraction $(\%)$, mean $(\mathrm{SD})$ & $60.7(13.7)$ & & $60.8(13.6)$ & & $60.5(13.6)$ & \\
\hline Depressed EF & 690 & 17.4 & 454 & 17.4 & 236 & 17.5 \\
\hline \multicolumn{7}{|l|}{ NYHA class } \\
\hline I-II & 1288 & 34.5 & 831 & 33.9 & 457 & 35.6 \\
\hline III & 2246 & 60.2 & 1490 & 60.8 & 756 & 59 \\
\hline IV & 197 & 5.3 & 128 & 5.2 & 69 & 5.4 \\
\hline Severe PHT & 414 & 10.5 & 287 & 11 & 127 & 9.4 \\
\hline Involvement ascending aortic & 327 & 8.2 & 214 & 8.2 & 113 & 8.4 \\
\hline $\mathrm{MI}<30 \mathrm{~d}$ & 573 & 15.3 & 368 & 14.9 & 205 & 16.2 \\
\hline Cardiogenic shock & 76 & 1.9 & 58 & 2.2 & 18 & 1.3 \\
\hline IABP preoperative/intraoperative & 279 & 7.5 & 179 & 7.3 & 100 & 8 \\
\hline Endocarditis & 120 & 3 & 85 & 3.2 & 35 & 2.6 \\
\hline Heparin & 190 & 4.8 & 129 & 4.9 & 61 & 4.5 \\
\hline Coumarin & 635 & 16 & 428 & 16.3 & 207 & 15.3 \\
\hline Antiplatelets & 1538 & 38.7 & 1013 & 38.7 & 525 & 38.8 \\
\hline \multicolumn{7}{|l|}{ AdES quartile } \\
\hline$<4$ & 952 & 24.1 & 616 & 23.6 & 336 & 24.9 \\
\hline $4-5$ & 830 & 21 & 569 & 21.8 & 261 & 19.3 \\
\hline $6-7$ & 1362 & 34.4 & 893 & 34.3 & 469 & 34.7 \\
\hline$>7$ & 812 & 20.5 & 528 & 20.3 & 284 & 21 \\
\hline
\end{tabular}




\begin{tabular}{|c|c|c|c|c|c|c|}
\hline \multirow[b]{3}{*}{ Variables } & \multirow{2}{*}{\multicolumn{2}{|c|}{$\begin{array}{c}\text { Whole cohort } \\
\mathbf{N}=\mathbf{3 9 7 0}\end{array}$}} & \multirow{2}{*}{\multicolumn{2}{|c|}{$\begin{array}{c}\text { Model development } \\
\mathrm{n}=\mathbf{2 6 1 8}\end{array}$}} & \multirow{2}{*}{\multicolumn{2}{|c|}{$\begin{array}{c}\text { Model validation } \\
\mathrm{n}=\mathbf{1 3 5 2}\end{array}$}} \\
\hline & & & & & & \\
\hline & $\mathbf{n}$ & $\%$ & $\mathbf{n}$ & $\%$ & $\mathbf{n}$ & $\%$ \\
\hline \multicolumn{7}{|l|}{ logES quartile } \\
\hline$<2.5$ & 989 & 25 & 637 & 24.4 & 352 & 26.1 \\
\hline $2.5-4.9$ & 989 & 25 & 674 & 25.9 & 315 & 23.3 \\
\hline $5.0-9.9$ & 992 & 25.1 & 648 & 24.9 & 344 & 25.5 \\
\hline$>9.9$ & 986 & 24.9 & 647 & 24.8 & 339 & 25.1 \\
\hline Preop stay, d, median (IQR) & $2(1-3)$ & & $2(1-3)$ & & $2(1-2)$ & \\
\hline \multicolumn{7}{|l|}{ Priority } \\
\hline Elective & 2199 & 55.7 & 1449 & 55.7 & 750 & 55.6 \\
\hline Inpatient & 1404 & 35.5 & 928 & 35.7 & 476 & 35.3 \\
\hline Urgent/emergent & 347 & 8.8 & 225 & 8.6 & 122 & 9.1 \\
\hline Previous cardiac surgery & 474 & 12.1 & 314 & 12.2 & 160 & 12 \\
\hline \multicolumn{7}{|l|}{ Intraoperative variables } \\
\hline $\mathrm{CBP}$ & 2585 & 65.1 & 1700 & 64.9 & 885 & 65.5 \\
\hline CPB time, min, mean (SD) & $54(51.3)$ & & $53.8(51.7)$ & & $54.1(50.4)$ & \\
\hline \multicolumn{7}{|l|}{$\mathrm{CBP}$ time range, min, in quartiles } \\
\hline 0 & 1408 & 36.1 & 938 & 36.4 & 470 & 35.4 \\
\hline $1-55$ & 555 & 14.2 & 375 & 14.6 & 180 & 13.5 \\
\hline $56-83$ & 970 & 24.8 & 623 & 24.2 & 347 & 26.1 \\
\hline$>83$ & 972 & 24.9 & 640 & 24.8 & 332 & 25 \\
\hline Ischemia or aortic crossclamp time, min, mean (SD) & $39.7(38.3)$ & & $39.4(38.3)$ & & $39.9(38.2)$ & \\
\hline \multicolumn{7}{|l|}{ Crossclamp time, min, in quartiles } \\
\hline 0 & 1499 & 37.8 & 999 & 38.2 & 500 & 37.1 \\
\hline $1-40$ & 484 & 12.2 & 317 & 12.1 & 167 & 12.4 \\
\hline $41-63$ & 1007 & 25.4 & 659 & 25.2 & 348 & 25.8 \\
\hline$>64$ & 977 & 24.6 & 643 & 24.6 & 334 & 24.8 \\
\hline \multicolumn{7}{|l|}{ Procedures } \\
\hline CABG & 1360 & 34.3 & 894 & 34.1 & 466 & 34.5 \\
\hline Valve & 1693 & 42.6 & 1101 & 42.1 & 592 & 43.8 \\
\hline Ascending aortic & 391 & 9.8 & 258 & 9.9 & 133 & 9.8 \\
\hline Combined & 300 & 7.6 & 209 & 8 & 91 & 6.7 \\
\hline Other & 226 & 5.7 & 156 & 6 & 70 & 5.2 \\
\hline No CABG & 2610 & 65.7 & 1724 & 65.9 & 886 & 65.5 \\
\hline Bilateral IMA & 269 & 6.8 & 160 & 6.1 & 109 & 8.1 \\
\hline IMA & 1618 & 40.8 & 1069 & 40.8 & 549 & 40.6 \\
\hline Valve & 2299 & 57.9 & 1513 & 57.8 & 786 & 58.1 \\
\hline \multicolumn{7}{|l|}{ Postoperative variables } \\
\hline Reoperation for bleeding or for tamponade & 233 & 6 & 140 & 5.3 & 93 & 6.9 \\
\hline Reoperation for bleeding & 165 & 4.16 & 101 & 3.86 & 64 & 4.7 \\
\hline Surgical drainage, cc $24 \mathrm{~h}$, mean (SD) & $546.8(390.3)$ & & $549.8(381.5)$ & & $540.9(406.8)$ & \\
\hline Reoperation for tamponade & 77 & 2 & 45 & 1.7 & 32 & 2.4 \\
\hline Vasopressors $>24 \mathrm{~h}$ & 201 & 5 & 129 & 4.9 & 72 & 5.3 \\
\hline Intubation $>24 \mathrm{~h}$ & 338 & 9 & 219 & 8.4 & 119 & 8.8 \\
\hline \multicolumn{7}{|l|}{ Duration of intubation } \\
\hline $6-12 \mathrm{~h}$ & 1495 & 40.5 & 1003 & 41.5 & 492 & 38.7 \\
\hline $12-24 \mathrm{~h}$ & 1850 & 50.2 & 1199 & 49.6 & 651 & 51.3 \\
\hline $24-48 \mathrm{~h}$ & 196 & 5.3 & 127 & 5.3 & 69 & 5.4 \\
\hline $48-72 \mathrm{~h}$ & 51 & 1.4 & 32 & 1.3 & 19 & 1.5 \\
\hline $3-7 d$ & 42 & 1.1 & 24 & 1 & 18 & 1.4 \\
\hline$>7 \mathrm{~d}$ & 54 & 1.5 & 33 & 1.4 & 21 & 1.7 \\
\hline Status at discharge, dead & 202 & 5.1 & 136 & 5.2 & 66 & 4.9 \\
\hline Days of ICU stay, median (IQR) & $1(1-3)$ & & $1(1-3)$ & & $1(1-3)$ & \\
\hline Days of hospital stay, median (IQR) & $8(6-12)$ & & $8(6-12)$ & & $8(6-12)$ & \\
\hline
\end{tabular}

$S D$, Standard deviation; $B M I$, body mass index; COPD, chronic obstructive pulmonary disease; $H b$, hemoglobin; $E F$, ejection fraction; $N Y H A$, New York Heart Association; $P H T$, pulmonary hypertension; $M I$, myocardial infarction; IABP, intra-aortic balloon pump; AdES, additive EuroSCORE; logES, logistic EuroSCORE; IQR, interquartile range; $C B P$, cardiopulmonary bypass pump; $C P B$, cardiopulmonary bypass; $C A B G$, coronary artery bypass graft; $I M A$, internal mammary artery; $I C U$, intensive care unit. 
TABLE E2. Characteristics of the whole patient cohort during the study period $(n=3970)$

\begin{tabular}{|c|c|c|c|c|c|c|c|c|c|c|c|c|c|c|}
\hline \multirow[b]{2}{*}{ Variable } & \multicolumn{2}{|c|}{2005} & \multicolumn{2}{|c|}{2006} & \multicolumn{2}{|c|}{2007} & \multicolumn{2}{|c|}{2008} & \multicolumn{2}{|c|}{2009} & \multicolumn{2}{|c|}{2010} & \multicolumn{2}{|c|}{2011} \\
\hline & $\mathbf{n}$ & $\%$ & $\mathbf{n}$ & $\%$ & $\mathbf{n}$ & $\%$ & $\mathbf{n}$ & $\%$ & $\mathbf{n}$ & $\%$ & $\mathbf{n}$ & $\%$ & $\mathbf{n}$ & $\%$ \\
\hline Sex (male) & 449 & 63.2 & 376 & 65.4 & 392 & 63.7 & 329 & 59.6 & 348 & 64.0 & 341 & 63.9 & 277 & 63.0 \\
\hline Age $>70 y$ & 309 & 43.5 & 271 & 47.2 & 276 & 44.9 & 249 & 45.1 & 257 & 47.2 & 254 & 47.6 & 211 & 48.0 \\
\hline DM & 198 & 28.4 & 158 & 27.8 & 172 & 28.2 & 172 & 31.4 & 151 & 27.8 & 153 & 28.7 & 134 & 30.5 \\
\hline COPD & 72 & 10.2 & 60 & 10.4 & 66 & 10.8 & 42 & 7.6 & 51 & 9.4 & 49 & 9.2 & 41 & 9.3 \\
\hline Antiplatelets & 303 & 42.7 & 225 & 39.1 & 236 & 38.4 & 205 & 37.1 & 207 & 38.1 & 189 & 35.4 & 173 & 39.3 \\
\hline Urgent/emergent priority & 62 & 8.7 & 60 & 10.4 & 45 & 7.3 & 47 & 8.6 & 55 & 10.1 & 43 & 8.1 & 35 & 8.2 \\
\hline CABG & 324 & 45.6 & 271 & 47.1 & 264 & 42.9 & 252 & 45.7 & 217 & 39.9 & 205 & 38.4 & 168 & 38.2 \\
\hline No CABG surgery & 443 & 62.4 & 359 & 62.4 & 404 & 65.7 & 339 & 61.4 & 375 & 68.9 & 375 & 70.2 & 315 & 71.6 \\
\hline $\mathrm{CPB}$ & 443 & 62.4 & 352 & 61.2 & 403 & 65.5 & 340 & 61.6 & 376 & 69.1 & 369 & 69.1 & 302 & 68.6 \\
\hline Intubation $>24 \mathrm{~h}$ & 39 & 5.5 & 48 & 8.3 & 49 & 8.0 & 49 & 8.9 & 71 & 13.1 & 46 & 8.6 & 36 & 8.2 \\
\hline Emergency reoperation $<24 \mathrm{~h}$ & 40 & 5.6 & 40 & 7.0 & 34 & 5.5 & 26 & 4.7 & 36 & 6.6 & 36 & 6.7 & 21 & 4.8 \\
\hline BMI median (IQR) & $26.6(2$ & 4-29.2) & $26.2(2$ & 2-29.3) & $26.8(2$ & $4-29.3)$ & $26.8(24$ & $-29.7)$ & $26.6(24$ & $2-29.4)$ & 26.8 & 4-29.7) & $27.4(24$ & $2-30.3)$ \\
\hline AdES median (IQR) & & & & & & 8) & $6(4$ & & $6(4$ & & $6(4-8)$ & & $6(4$ & \\
\hline $\operatorname{logES}$ median (IQR) & $4.6(2$ & 3-8.6) & $5.1(2$ & $4-10)$ & $5.5(2$ & $5-10.2)$ & $5.1(2$ & $-9.8)$ & $5.5(2$ & $-11.8)$ & $4.7(2.4-9$ & & $5.1(2$ & $5-9.1)$ \\
\hline CPB time median (IQR) & 47( & $-70)$ & 50( & -74) & 56( & $-80)$ & $55(C$ & $-89)$ & $66(0$ & $-96)$ & $65(0-92)$ & & $61(0$ & $-93)$ \\
\hline Ischemia time median (IQR) & 35( & $-53)$ & 36.5 & -59) & 40( & $-60)$ & $41(C$ & $-64)$ & $49(0$ & -74) & $48(0-72)$ & & $46(C$ & $-73)$ \\
\hline
\end{tabular}

$D M$, Diabetes mellitus; $C O P D$, chronic obstructive pulmonary disease; $C A B G$, coronary artery bypass graft; $C P B$, cardiopulmonary bypass; $B M I$, body mass index; $I Q R$, interquartile range; $A d E S$, additive EuroSCORE; logES, logistic EuroSCORE.

TABLE E3. Impact of mediastinitis in the global cohort $(n=3970)$

\begin{tabular}{|c|c|c|c|c|}
\hline & $\begin{array}{c}\text { Mediastinitis } \\
\%(\mathbf{n} / \mathbf{N})\end{array}$ & $\begin{array}{c}\text { No mediastinitis } \\
\%(\mathbf{n} / \mathbf{N})\end{array}$ & OR $(95 \%$ CI $)$ & $P$ value \\
\hline Readmission to ICU & $71.3(67 / 94)$ & $2.1(81 / 3876)$ & $116.3(70.7-191.3)$ & $<.001$ \\
\hline Readmission to hospital $<30 \mathrm{~d}$ & $22.4(21 / 94)$ & $1.7(66 / 3876)$ & $16.6(9.6-28.6)$ & $<.001$ \\
\hline ICU length of stay, median (IQR) & $5(2-31)$ & $1(1-3)$ & $1.04(1.03-1.05)$ & $<.001$ \\
\hline Hospital length of stay, median (IQR) & $50.5(34.2-75.2)$ & $5.5(2-31)$ & $1.04(1.03-1.05)$ & $<.001$ \\
\hline Mortality, $30 \mathrm{~d}$ & $27.7(26 / 94)$ & $4.5(202 / 3876)$ & $8.0(5.0-12.9)$ & $<.001$ \\
\hline
\end{tabular}

$O R$, Odds ratio; $C I$, confidence interval; $I C U$, intensive care unit; $I Q R$, interquartile range.

TABLE E4. Poststernotomy mediastinitis risk categories defined for our model development patient cohort $(n=2618)$

\begin{tabular}{lccc}
\hline \multicolumn{1}{c}{ Risk level } & Score & OR $(\mathbf{9 5} \% \mathbf{C I})$ & $\boldsymbol{P}$ value \\
\hline Low & $0-5$ & 1 & $<.001$ \\
Intermediate & $6-9$ & $7.24(4.05-12.93)$ & $<.001$ \\
High & $\geq 10$ & $17.58(7.84-39.40)$ & $<.001$ \\
\hline
\end{tabular}

$O R$, Odds ratio; $C I$, confidence interval. 
TABLE E5. Correlation between Med-Score 24 scores and mediastinitis probability in the whole and model development cohorts

\begin{tabular}{|c|c|c|c|}
\hline \multicolumn{2}{|c|}{ Whole cohort } & \multicolumn{2}{|c|}{ Model development cohort } \\
\hline Score $(\%)$ & $\mathbf{n} / \mathbf{N}$ & Score $(\%)$ & $\mathbf{n} / \mathbf{N}$ \\
\hline $0(0.7)$ & $4 / 596$ & $0(0.5)$ & $2 / 400$ \\
\hline $2(1.2)$ & $13 / 1064$ & $2(1)$ & $7 / 688$ \\
\hline $3(0.4)$ & $1 / 280$ & $3(0.5)$ & $1 / 198$ \\
\hline $4(1.4)$ & $12 / 846$ & $4(1.2)$ & $7 / 568$ \\
\hline $5(0.9)$ & $3 / 321$ & $5(1)$ & $2 / 203$ \\
\hline $6(5.4)$ & $18 / 331$ & $6(5.6)$ & $12 / 215$ \\
\hline $7(6.7)$ & $14 / 210$ & $7(8)$ & $11 / 137$ \\
\hline $8(5.8)$ & $6 / 103$ & $8(4.1)$ & $3 / 73$ \\
\hline $9(5.8)$ & $6 / 103$ & $9(7.7)$ & $5 / 65$ \\
\hline $10(18.4)$ & $7 / 38$ & $10(11.5)$ & $3 / 26$ \\
\hline $11(12.2)$ & $5 / 41$ & $11(14.3)$ & $4 / 28$ \\
\hline 12 (10) & $1 / 10$ & $12(0)$ & $0 / 3$ \\
\hline $13(5.6)$ & $1 / 18$ & 13 (10) & $1 / 10$ \\
\hline $14(40)$ & $2 / 5$ & $14(100)$ & $2 / 2$ \\
\hline $15(33.3)$ & $1 / 3$ & $15(0)$ & $0 / 2$ \\
\hline $17(0)$ & $0 / 1$ & $17(0)$ & $0 / 0$ \\
\hline
\end{tabular}

TABLE E6. Score ranges according to number of risk factors in a patient

\begin{tabular}{lcc}
\hline \multirow{2}{*}{ No. of risk factors } & \multicolumn{2}{c}{ Med-Score 24 } \\
\cline { 2 - 3 } & Minimum & Maximum \\
\hline 0 & 0.00 & 0.00 \\
\hline & 2.00 & 4.00 \\
\hline 3 & 4.00 & 8.00 \\
4 & 6.00 & 11.00 \\
\hline 5 & 8.00 & 13.00 \\
6 & 11.00 & 15.00 \\
\hline & 15.00 & 17.00 \\
\hline
\end{tabular}

